this case with Graham Spinardi) shows that this argument rests on a very particular account of the nature of science and technology. They argue that the science and technology of nuclear weapons relies on the constant performance of particular sorts of experiments, and a great deal of highly specific tacit knowledge. Nuclear technology has been built up in only a very few states, and with extraordinary difficulty. The capacity to build weapons could in practice disappear, even if all the science stayed in the public domain. The ultimate science-based weapon relies on much more than written knowledge and standard engineering capabilities.

In some ways MacKenzie is attacking straw men in his discussion of technological innovation, but this is not really a criticism of MacKenzie. It is, rather, a criticism of the way that we think and write about technology. We look at technologies in much the same way as they appear in advertisements: as fully formed, perfect and inevitable developments following a logic of technical development. The real world of new machines is very different, as we know from our own experience as well as from historical studies and MacKenzie's detailed empirical work.

David Edgerton is at the Centre for the History of Science, Technology and Medicine, Imperial College, London SW7 2AZ, UK.

\title{
Taking things at interface value
}

\section{Graham Farmelo}

Software for the Self: Culture and Technology. By Anthony Smith. Faber: 1996. Pp. 128. £7.99, (pbk).

Cultural Babbage: Technology, Time and Invention. Edited by Francis Spufford and Jenny Uglow. Faber: 1996. Pp. 290. £15.99, \$24.95 (pbk).

ACCORDING to Oscar Wilde, "all art is quite useless", and, to the extent that such a brutally utilitarian view is valid, the same is true of culture. Because part of the value of culture lies in its transcendence of the material world, it appears to be very different from technology, which is concerned only with the materially useful. What, then, is the place of technology in culture?

Information technology - the defining technology of our age - poses particularly difficult problems for the cultural theorist. Something so widely available to so many is not readily accommodated in a view of a culture based on what that austere critic Matthew Arnold identified as "the best that has been known and said in the world". It is unlikely that he would have found much "sweetness and light" in the hegemony of the silicon chip.

In Software for the Self, Anthony Smith examines the slippery concept of culture and examines its meaning in the light of modern technological developments in the media. The book is a collection of thoughtful and eclectic essays based on lectures the author gave in 1994, in a series named after T. S. Eliot, Arnold's twentiethcentury standard-bearer. Smith begins by explaining how the 'arts' - that broadest of portmanteau terms - came to be central to the usual narrow idea of what constitutes cultural activity. This leads him to analyse how the century's most pervasive cultural revolution has been effected electromagnetically, through the introduction of broadcasting media.

Smith makes a powerful case for the

importance of the concept of information in analysing the modern cultural agenda. He points out that information is a classic example of a transforming concept that, like chaos, the unconscious mind and the uncertainty principle, "rapidly invades every science, and its analogues and derivative images spread through the arts and into political discourse, eventually arriving at the gates of government". Scarcely a branch of modern industrial society has not been transformed by its own contact with the new paradigm of information, and we are all trying to come to terms with the potential of a global communica-

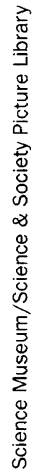

\section{IMAGE UNAVAILABLE FOR COPYRIGHT REASONS}

Prototype computer: Babbage's first "Difference Engine".

tions network, which promises to make most media readily available to anyone with a computer.

Smith points out that, with virtual reality still in its infancy and the potential for interactivity with the conventional media still largely unexplored, there are more cultural upheavals in the offing. Yet he pays little attention to the effects that the growth in the quantity of information in the media have had on the quality of the material purveyed. Has anything of significant literary worth ever been created in cyberspace? Perhaps it is a coincidence that it is in the adolescence of the digital age that such a question is regarded as misconceived or, at least, outré.

Smith has given us a valuable new perspective on contemporary culture in these fine essays, all happily devoid of jargon and snobbery. It is regrettable that he been so badly let down by his publishers. They tell us next to nothing about him, fail to provide him with an index (essential in a work of this breadth) and make no effort to package his book so that it might stand a chance of attracting the wide audience it deserves.

The unity of purpose that gives such collective power to Software for the Self is not evident in Cultural Babbage, a collection of pieces that idiosyncratically explore connections between science and technology (rarely distinguished here, regrettably) and various branches of the arts and humanities. Its 14 contributors include critics, poets, biographers and historians, each of them plainly at home in both of C. P. Snow's 'two cultures', in so far as they exist separately.

The theme of most of these essays is the place in the firmament of culture occupied by technology, in particular by machines and other inventions. As the title of the collection hints, a central figure here is Charles Babbage, the irascible polymath best remembered for his failure to build a complete version of what would probably have been regarded as the first computer. Doron Swade's elegant and scrupulously fair analysis of Babbage's reputation is followed by the highlight of the volume, Simon Schaffer's "Babbage's dancer and the impresarios of mechanism". This densely argued piece looks at how the tough-minded Babbage and his peers were fascinated by apparently frivolous automata, such as the silver danseuse that he exhibited, close to the unfinished portion of his first 'Difference Engine', in his London salon. Schaffer links this fascination with the perception of machine intelligence, which he convincingly argues "hinges on the cultural invisibility of the human skills which accompany them".

The quality of the other pieces is uneven but they do include some gems, notably Lavinia Greenlaw's look at the connections between science and poetry, Neil Belton's analysis of the British scorn of the scientific, and Jon Katz's advocacy of the republican revolutionary Thomas Paine as the spiritual father of the Internet. The excellent index makes the collection a valuable work of reference, although the bibliographical information is disappointing, to say the least.

In her introduction, Jenny Uglow remarks that the essays are "ballasted by 
detail but untethered by the ropes of academic apparatus" so that "they let the balloon of ideas float free across the orthodox science/arts divide". During our repeated crossings of the Snow-line, we enjoy a stimulating and intermittently exhilarating ride, although it is never quite clear where the balloon is heading.

Graham Farmelo is at the Science Museum, Exhibition Road, London SW7 2DD, UK.

\section{Body work}

\section{David Goodstein and Judith Goodstein}

Twentieth Century Physics: Volumes I, II and III. Edited by Laurie M. Brown, Abraham Pais and Brian Pippard. Institute of Physics/American Institute of Physics: 1995. Pp. 2,059. £250, \$400 (3 vols).

THIs book is a monumental undertaking. In fact, speaking of undertaking, it is an obituary written before the body is cold. A few even think the heart may still be beating. Nevertheless, it will serve a number of important purposes.

With more than 2,000 pages in three volumes, Twentieth Century Physics is comprehensive. It opens with an essay by Brian Pippard on "Physics in 1900", followed by Abraham Pais on "Introducing Atoms and their Nuclei" and, a bit later in the volume, Laurie Brown on "Nuclear Forces, Mesons, and Isospin Symmetry". The third volume closes with philosophical essays on the history, substance and social structure of twentieth-century physics by Philip Anderson, Steven Weinberg and John Ziman. In between, the various fields of physics and closely related sciences (medical physics, geophysics) are covered by their practitioners. The level is uncompromisingly technical. This is not a reference for schoolchildren or journalists.

What is it then? According to the editors, they have created it because the history of physics is too important to be left to the historians. This, they imply, is history as it ought to be written, done by the pros, the participants who are qualified to decide what matters and what doesn't. In short, this is the peculiar view of history seen in a thousand physics textbooks, distilled to an undiluted essence. If nothing else, it shows us vividly how physicists wish to see their craft portrayed.

Physics, we learn, does not depend on the people who discovered it, or on the conditions in which they lived. Pais quotes a biographer of Rutherford: "People ask... what was the man like, did he really look like a farmer.... None of these things really matter." Physics, then, in a first approximation, is a body of knowledge about things, thoroughly drained of flesh and blood.

Ah, but that won't do of course. The physicists' egos won't permit it. Impersonal phenomena, such as Compton scattering or the Mössbauer effect, get named after real people. In these volumes, the technique for reintroducing life onto the barren planet of physics is some 63 biographical sketches, set off in boxes, scattered through the three volumes. In fact, this is one of the most important functions that the editors and their contributors have taken on. This is an anointing of the winners, and an omitting of the losers. It is, at the very least, an updating of the scoreboard in the great and noble competition of physics.

Of the 63 sketches, 61 are about white, European or American males (Ryogo Kubo and Hideki Yukawa are the exceptions). Incredibly, Robert Millikan is omitted, although his student Carl Anderson is included (can the positron really be more important than the electron?). Beyond this galaxy of superstars, every physicist who picks up this set of volumes will flip first to the name index to see if he's made it (they are nearly all he's). Brown, Pais and Pippard had better be prepared to take some heat.

It is hard to imagine a history of anything in the twentieth century that omits completely to mention that great cataclysmic event at the middle of the century, the Second World War. This is especially true of physics, where the war had immense effects, both positive and negative. Twentieth Century Physics tries hard to ignore it, and almost succeeds, but not quite. For example, of Max Planck, we are told that "he defended German science in the difficult times of the Third Reich", and we learn that Nernst's school, "sadly depleted by Nazi anti-Jewish measures, flourished in exile". Nevertheless, the Second World War doesn't make the subject index, and neither does Los Alamos.

All of the above is more or less made inevitable by the nature of the subject and the task that the editors and contributors set for themselves. Within the limits of that task, their accomplishment is impressive. As one might expect, the contributed articles are a bit uneven. Most read like physics review articles, typically found in the journal Reviews of Modern Physics. All are professional and authoritative, although a few tend to re-draw the map slightly to place the author closer to the centre. Dividing up the subject matter must have been difficult. For example, the subdiscipline that calls itself 'condensed matter physics' is represented by articles on crystallography by William Cochran, statistical mechanics (largely critical phenomena) by Cyril Domb, nonequilibrium statistical mechanics by Max Dresden, superfluids by A. J. Leggett, phonons and spin waves by R. A. Cowley and Pippard, magnetism by K. W. H. Stevens, electrons in solids by Pippard, materials by Robert Cahn and polymers and the like by P. G. de Gennes. Cross references are achieved by boxes in the margin saying "see also page $\mathrm{xxx}$ ".

Nobody is going to read through these three volumes from cover to cover. Not even we managed that, despite heroic efforts and gallons of black coffee. But many physicists will dip into them and read sections with real pleasure. The work will also provide source material to spruce up courses and seminars with a bit of historical introduction. All this is very much to the good. The only remaining question is will it serve the main purpose the editors had in mind?

It seems clear that the editors intend their volumes to survey the territory and lay out the road maps and instructions by means of which future historians of science will find their way around physics in the twentieth century. Given the generally abysmal state of the secondary historical literature in this field, they may well succeed, up to a point. These essays are not a bad way to get an initial overall orientation to what happened in a given area. But real historians will want much more than is available here. Physicists can and do speak with confidence and authority (some would say arrogance) about their discipline, and this series is a perfect example of that. Nevertheless, this much will remain true: historians always have the last word. When historians write the story of twentieth-century physics, they will put the flesh and blood back into it.

David Goodstein and Judith Goodstein are at the California Institute of Technology, Pasadena, California 91125, USA.

\section{New and notable}

Fire in the Mind: Science, Faith and the

Search for Order by George Johnson. Viking, £18. A New York Times science writer's overview of some of the emerging new ideas in physics and biology coming out of Los Alamos National Laboratories and the Santa Fe Institute in New Mexico.

\section{Charles Darwin's Letters: A Selection} 1825-1859 edited by Frederick

Burkhardt. Cambridge University Press, £45, \$54.95 (hbk), £15.95, \$19.95

(pbk). Letters taken from the monumental Cambridge edition of The Correspondence which reveal the human story behind the Origin of Species.

Dinosaur in a Haystack: Reflections in Natural History by Stephen Jay Gould. Harmony/Cape, \$25. The author's seventh collection of masterly musings on evolution and other natural phenomena, culled from his monthly column in Natural History magazine. 